\title{
Phase Transformation and Carbide Precipitation of Functional Gradient Semi-solid 9Cr18 Steel
}

\author{
Yong-Jin Wang ${ }^{1,2} \cdot$ Ren-Bo Song $^{1} \cdot$ Ren-Feng Song ${ }^{3}$ \\ Received: 25 December 2017 / Revised: 23 January 2018/Published online: 9 April 2018 \\ (C) The Chinese Society for Metals and Springer-Verlag GmbH Germany, part of Springer Nature 2018
}

\begin{abstract}
The unique phase transformation and carbide evolution in $9 \mathrm{Cr} 18$ steel were investigated during semi-solid forming and subsequent heat treatment. The functional gradient thixoforging $9 \mathrm{Cr} 18$ component was divided into inner area and edge area. Microstructure evolution was different at each area. After semi-solid cooling, the solid particles in the inner area were retained as meta-austenite. During annealing, $M_{23} \mathrm{C}_{6}$ carbide began to precipitate when temperature reached $700{ }^{\circ} \mathrm{C}$. Martensite transformation occurred when temperature reached $800{ }^{\circ} \mathrm{C}$. The occurrence of $M_{23} \mathrm{C}_{6}$ carbide and martensite structure would be harmful to the mechanical properties of inner area. In the edge area, the liquid underwent eutectic transformation to form bar-shape $M_{7} \mathrm{C}_{3}$ carbide and secondary austenite after semi-solid cooling. The width of bar-shape carbide would decrease during annealing. By controlling the carbide evolution, we could tailor the functional gradient material with required property.
\end{abstract}

Keywords Semi-solid forming $\cdot$ Solid/liquid phase $\cdot$ Annealing $\cdot$ Carbide precipitation

\section{Introduction}

Semi-solid forming (SSF) is considered as a conceivable alternative to conventional forging or casting due to its lower forming load and near-net shape properties [1,2]. At semi-solid temperature range, non-dendritic microstructure of solid spheroids and liquid film demonstrates thixotropic flow behavior, which will help the filling of dies [3]. Researchers have proposed several methods to obtain the non-dendritic microstructure, for example mechanical stirring, magneto hydrodynamic stirring and SIMA (straininduced melt activation) [4]. SSF can be divided into rheoforming and thixoforming due to the difference of concrete procedures [5]. Up to now, SSF of light weigh

Available online at http://link.springer.com/journal/40195.

Ren-Bo Song

songrb@mater.ustb.edu.cn

1 School of Materials Science and Engineering, University of Science and Technology Beijing, Beijing 100083, China

2 Institute of Industrial Science, The University of Tokyo, Komaba 4-6-1, Meguro, Tokyo 153-8505, Japan

3 Ansteel Mining Engineering Corporation, Anshan 114004, China alloys such as aluminum or magnesium has been taken into industrial application [6]. However, the improvement on SSF of high melting alloys is faced with many difficulties such as narrow semi-solid temperature window, suitable tool material [7].

One special challenge for SSF of steel is the complex microstructure evolution. As can be seen from the $\mathrm{Fe}-\mathrm{C}$ diagram, phase transformation occurs during heating or cooling. SSF of steel will undergo several heat cycles. Besides, as a thermo-related behavior, heat treatment procedures are usually conducted for SSF specimen to obtain desired microstructure and properties [8]. Many researchers are focusing on several kinds of high alloying steels such as X210CrW12, SKD61. The alloying elements in the steel make it more difficult to analyze the microstructure evolution. Gu et al. [9] investigated the flow behavior of thixoextrusion M2 steel. Uhlenhaut et al. [10] studied the structure of a hypoeutectic chromium steel in the semisolid state. With the help of thermo-mechanical simulation, they analyzed the multiphase microstructures after isothermal aging. Rogal et al. [11] investigated the phase transformation of $100 \mathrm{Cr} 6$ steel after different strategies of semi-solid cooling. The research indicates that carbide precipitation is inevitable during the whole heat cycles of SSF. Carbide precipitation will affect the microstructure 
and mechanical properties [12]. But, there is rare investigation on carbide evolution during SSF of steel now. $9 \mathrm{Cr} 18$ steel is a kind of $\mathrm{Fe}-\mathrm{Cr}-\mathrm{C}$ alloy, demonstrating a functional gradient property after semi-solid processing. For the $\mathrm{Fe}-\mathrm{Cr}-\mathrm{C}$ alloy, various kinds of $\mathrm{Cr}_{x} \mathrm{C}_{y}$ carbides precipitate during certain heat treatment procedures [13]. The chromium carbides will have a significant influence on the microstructure characterization and mechanical properties of final steel component [14]. SSF is a complex heat related process. Therefore, the precipitation road map of carbides in $\mathrm{Fe}-\mathrm{Cr}-\mathrm{C}$ alloy might be different as compared with conventional procedures. Since solid particles and melted liquid coexist at semi-solid state, phase transformation and precipitation of alloying elements should be concerned in solid phase and liquid phase, respectively. Having a better understanding of microstructure evolution is fundamental for SSF of steel.

The objective of this study is to investigate the phase transformation and carbide evolution during semi-solid cooling and subsequent heat treatment for $9 \mathrm{Cr} 18$ steel. The formation mechanism, morphology characterization of chromium carbides will be clarified and the relationship among carbide evolution, phase transformation and mechanical properties will be studied. The research will provide a basic understanding of carbide evolution during SSF of steel.

\section{Experimental Procedures}

The material is commercially produced 9Cr18 (AISI: 440C) stainless steel. The chemical composition is $0.97 \mathrm{C}$, $17.33 \mathrm{Cr}, 0.52 \mathrm{Si}, 0.02 \mathrm{P}, 0.005 \mathrm{~S}, 0.10 \mathrm{Al}, 0.16 \mathrm{Ni}, 0.12$ $\mathrm{Co}$ and balance $\mathrm{Fe}$ (wt\%). The whole temperature-time cycles of specimens are shown in Fig. 1. The 9Cr18 semisolid billet was prepared by wavelike sloping plate method [15]. Thixoforging process was conducted in a designed set-up [16]. A multi-diameter shaft could be fabricated as the two dies closed. The deformation region was designed to demonstrate the functional gradient properties. The two edges were holding areas with no deformation. More detailed information about the thixoforging process can be seen in Wang et al. [17]. Finally, thixoforging specimen was annealed at various temperatures of $200-1050{ }^{\circ} \mathrm{C}$ for $2 \mathrm{~h}$. For convenience, the specimens annealed at 200, 550, 700,800 and $1050{ }^{\circ} \mathrm{C}$ are referred to as T-200, T-550, T-700, T-800 and T-1050, respectively.

As shown in Fig. 1, specimens at the deformation region were machined to investigate the functional gradient properties. The specimens under different heat treatment procedures were polished and etched with Vilella's reagent $(1 \mathrm{~g}$ picric acid, $100 \mathrm{~mL}$ alcohol, $15 \mathrm{~mL}$ hydrochloric acid). Then, the microstructures were observed by optical microscopy (OM ZEISS Imager.M2m) and transmission electron microscopy (TEM JEM-2100) was used to observe the microstructure. TEM specimens were grinded to a thickness of $50 \mu \mathrm{m}$ and electropolished with a twin jet electropolisher (MTP-1A) at $-30{ }^{\circ} \mathrm{C}$ using a solution containing 95 vol. $\% \mathrm{C}_{2} \mathrm{H}_{5} \mathrm{OH}$ and 5 vol. $\% \mathrm{HClO}_{4}$. Vickers hardness tests were carried out on a HXD1000T tester for specimens under different heat treatment procedures. All the Vickers hardness tests were conducted in accordance with the standard of ASTM E384-2010e2. The observation and tests were performed on the inner area and edge area of each specimen, respectively.

DIL 805A high-resolution thermal dilatometer was utilized to analyze the microstructure evolution of thixoforging specimen. Dilatometer test was conducted at the specimen cutting from inner area of thixoforging component. The samples were heated to $1100{ }^{\circ} \mathrm{C}$ at slow heating rate of $0.15{ }^{\circ} \mathrm{C} / \mathrm{s}$. The tangent method was used to determine the phase transformation temperatures. Differential scanning calorimetry (DSC) test was also conducted to analyze the phase transformation of semi-solid $9 \mathrm{Cr} 18$ steel with a heat rate of $10{ }^{\circ} \mathrm{C} / \mathrm{min}$. X-ray diffraction (XRD: Rigaku SmartLab, $\mathrm{Cu}$ target, operated at $40 \mathrm{kV}$ and $150 \mathrm{~mA}$ with scanning speed $20 \% \mathrm{~min}$ ) was performed to understand the microstructure evolution after heat treatments.

The compression tests were performed using CMT5105 electronic universal experiment machine at a compression rate of $1 \mathrm{~mm} / \mathrm{min}$. The samples were machined from the inner area of thixoforging component (Fig. 1). The size of the samples was $\Phi 4 \times 6 \mathrm{~mm}$ following the standard of GB/T 7314-2005.

\section{Results}

\subsection{Microstructure and Phase Transformation}

9Cr18 steel, also known as AISI 440C, is a kind of martensitic stainless steel. Traditionally, heat treatment procedures for $9 \mathrm{Cr} 18$ products consist of quenching at $1050{ }^{\circ} \mathrm{C}$ and tempering at $200{ }^{\circ} \mathrm{C}$. However, heat cycles for semi-solid forming are quite different from traditional procedure [18]. Solid particles and melted liquid both exist at semi-solid temperature range. As shown in Fig. 2a, a distinct solid/liquid boundary exists. Former solid particles and solidified liquid were separated at the inner area and edge area after thixoforging, respectively. At semi-solid temperature state (about $1340{ }^{\circ} \mathrm{C}$ ), the higher amount of alloying elements will help to stabilize the solid austenite particles [16]. Thus, meta-austenite solid with over-saturated $\mathrm{Cr}, \mathrm{C}$ elements will be retained after water cooling. As for the melted liquid, it will suffer the eutectic 


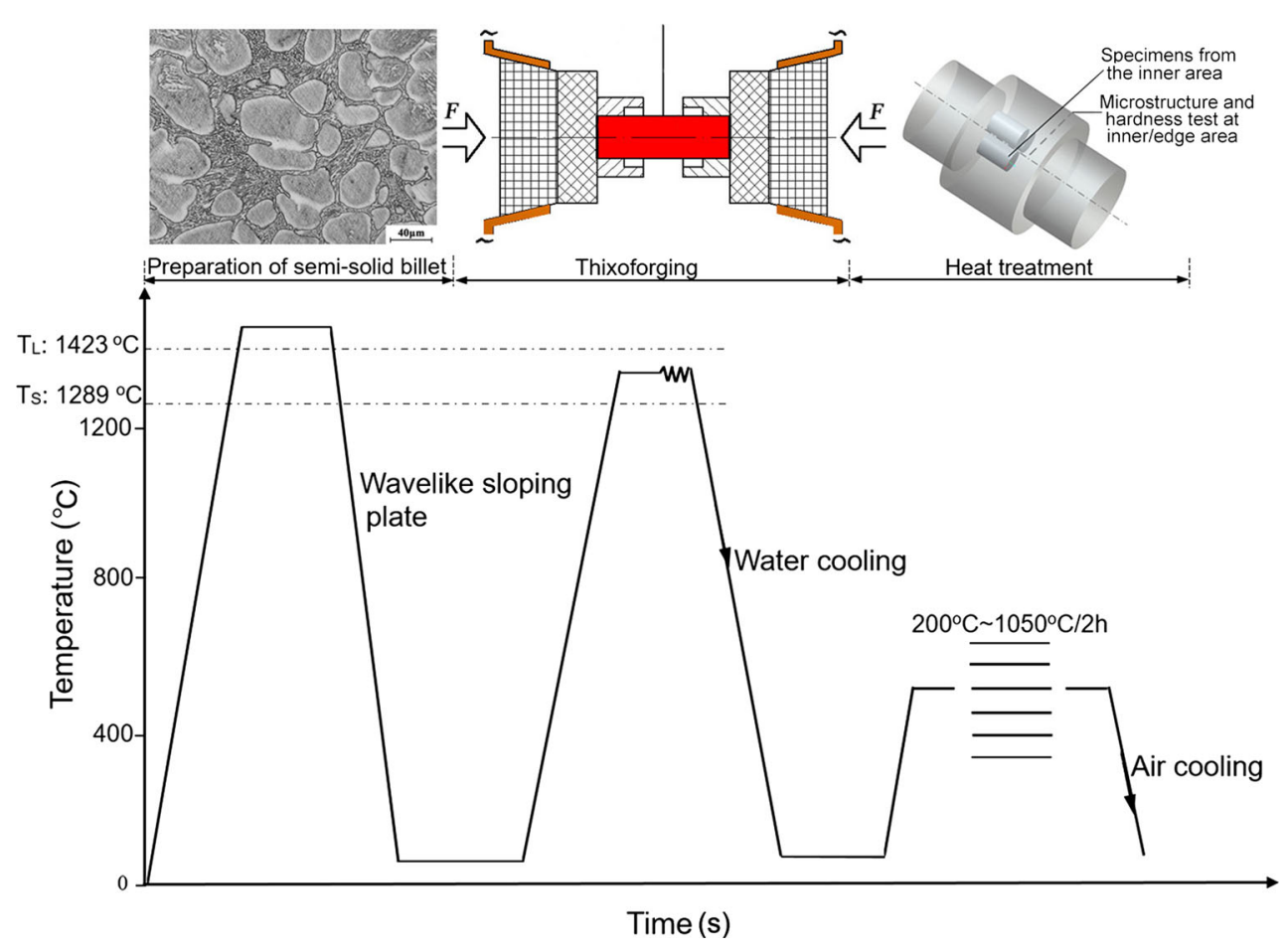

Fig. 1 Temperature-time cycle of the whole process

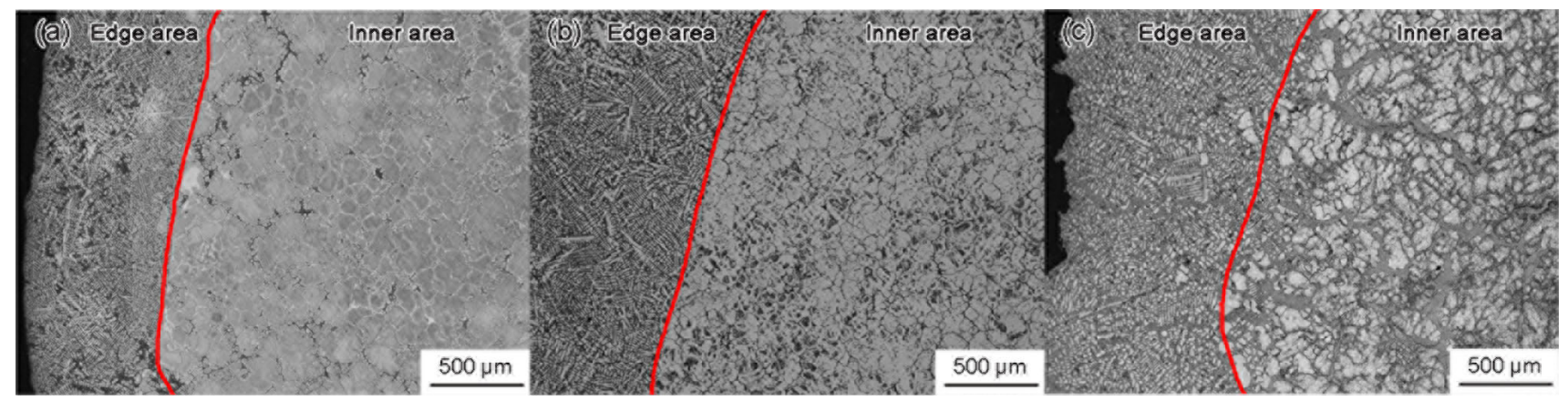

Fig. 2 Microstructures of thixoforging specimen a, and after different heat treatments: b $550{ }^{\circ} \mathrm{C}, \mathbf{c} 800{ }^{\circ} \mathrm{C}$

transformation $\left(\mathrm{L} \rightarrow \gamma+M_{7} C_{3}\right)$ during fast cooling [16]. Fine dendrite structure of secondary austenite and $M_{7} \mathrm{C}_{3}$ $\left((\mathrm{Cr}, \mathrm{Fe})_{7} \mathrm{C}_{3}\right)$ carbide will form after cooling [15]. As shown in Fig. 2b, c, the solid/liquid boundaries still exist after subsequent annealing. Fine dendrite structures in the outside of the boundaries also exist. At the inner area, no obvious change occurs after annealing at $550{ }^{\circ} \mathrm{C}$ as shown in Fig. 2b. But, shallow martensite structure can be seen inside the former austenite grains when annealing temperature increases up to $800{ }^{\circ} \mathrm{C}$. Previous study shows the inner austenite may transform into martensite due to the secondary hardening effect [19]. Detailed microstructure evolution will be discussed in the following.

The meta-stable microstructure of thixoforging specimen might lead to unique behavior during subsequent heat treatment. Thus, the phase transformation behavior in the inner area was determined by dilatometer experiment and DSC test. Initially, dilation increases linearly with the increase of temperature shown in Fig. 3a. When temperature increases up to around $700{ }^{\circ} \mathrm{C}$, a slower increase of dilation happens. Then, the dilation speed increases again after around $900{ }^{\circ} \mathrm{C}$. The nonlinear increase is an obvious indication of phase transformation [20]. The dilatometer test and DSC measurement are coupled for analysis. As shown in Fig. 3b, heat flow in DSC curve shows a variation from around 600 to $900{ }^{\circ} \mathrm{C}$ and two peaks can be seen at the mentioned temperature range. An exothermic peak occurs at $698{ }^{\circ} \mathrm{C}$. An endothermic peak is observed near $838{ }^{\circ} \mathrm{C}$. The results of dilatometry and DSC are in good agreement with one another. Figure 4 shows the XRD results from the inner area under different heat treatments. Predominant austenite structure can be observed for 

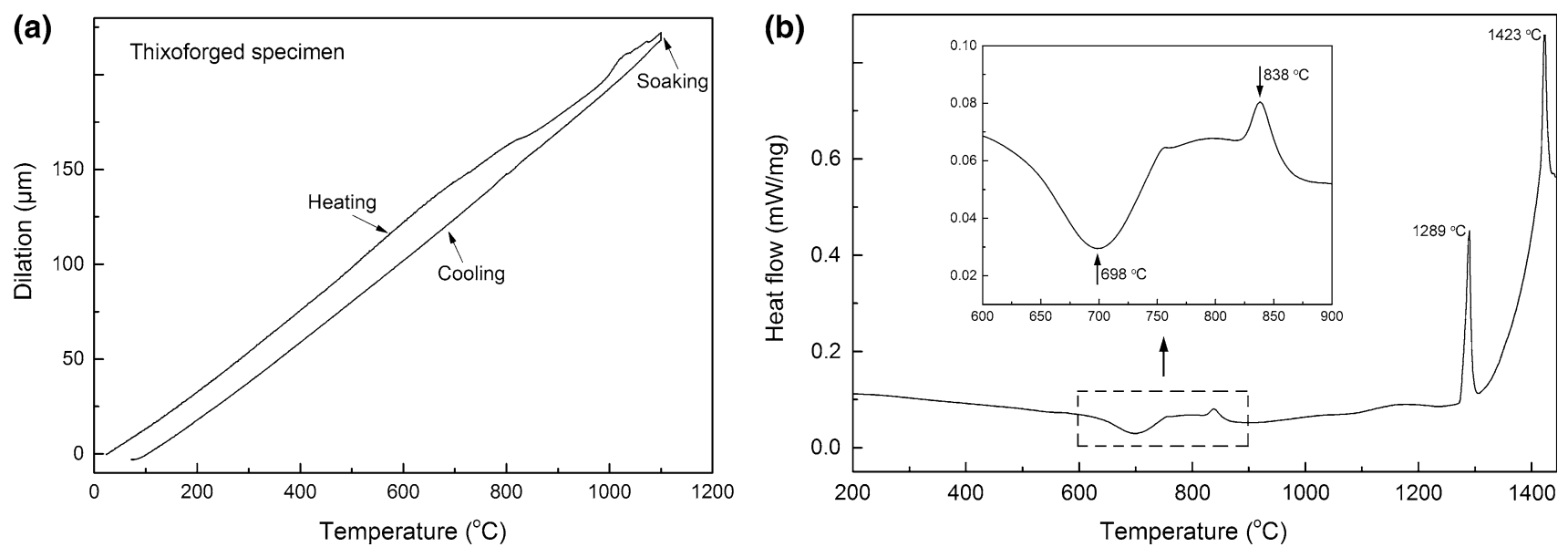

Fig. 3 a Dilatometric curve of inner area of thixoforging specimen; b DSC curve of 9Cr18 billet

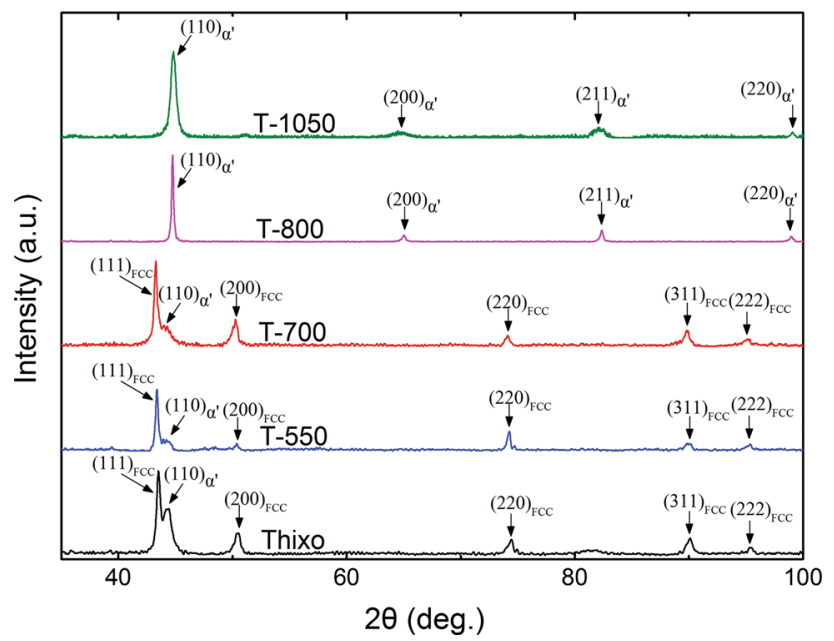

Fig. 4 XRD patterns from the inner area of specimens under different heat treatments

thixoforging, T-550 and T-700 specimens. For T-800 and $\mathrm{T}-1050$ specimens, the main structure has transformed into martensite phase. It might be difficult for XRD scanning to detect the carbide precipitation. Zhou et al. [21] also mentioned it is not easy to identify precipitation phase only through XRD. Carbides evolution will be discussed in the following section. As shown in Fig. 5, the microhardness at the inner area increases sharply from 700 to $800{ }^{\circ} \mathrm{C}$. When annealing temperature is lower than $700{ }^{\circ} \mathrm{C}$, hardness in the inner area remains at $300 \mathrm{HV}-400 \mathrm{HV}$ level. After annealing at 800 or $1050{ }^{\circ} \mathrm{C}$, hardness in the inner area reaches above $600 \mathrm{HV}$. While at the edge area, hardness remains at a high level even after annealing at $1050{ }^{\circ} \mathrm{C}$. Inner area and edge area demonstrate different properties during annealing.

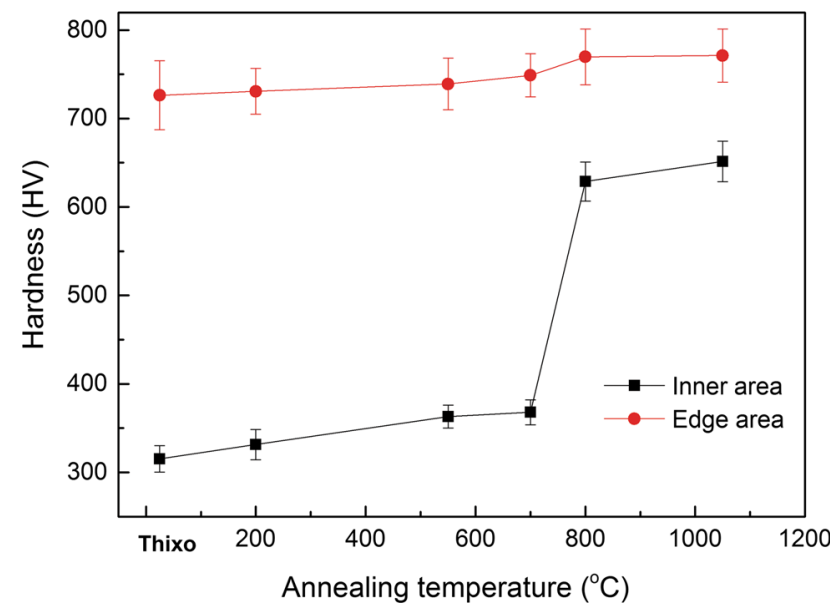

Fig. 5 Microhardness evolution of thixoforging specimen under different heat treatments

\subsection{Carbide Precipitation After Annealing at Different Temperatures}

The thixoforging specimen is in a meta-stable state due to the rapid cooling after thixoforging process. The oversaturated alloying elements may lead to carbide precipitation during annealing. Microstructure evolution in inner area and edge area is observed by TEM, respectively. TEM images from the inner area and edge area are quite different. In the inner area of thixoforging specimen (Fig. 6a), TEM observation and SAED confirm the FCC (face centered cubic) structure of the austenite. The austenite grain is clear with no precipitation. When the annealing temperature is lower than $550{ }^{\circ} \mathrm{C} \quad(\mathrm{T}-200, \mathrm{~T}-550)$, microstructure in the inner area does not change obviously as shown in Fig. 6b, c. When annealing temperature increases up to $700{ }^{\circ} \mathrm{C}$ (Fig. 7a), carbide precipitation occurs. There are plenty of granular carbides with a size less than $82 \mathrm{~nm}$. It is confirmed as $M_{23} \mathrm{C}_{6}\left((\mathrm{Cr}, \mathrm{Fe})_{23} \mathrm{C}_{6}\right)$ 

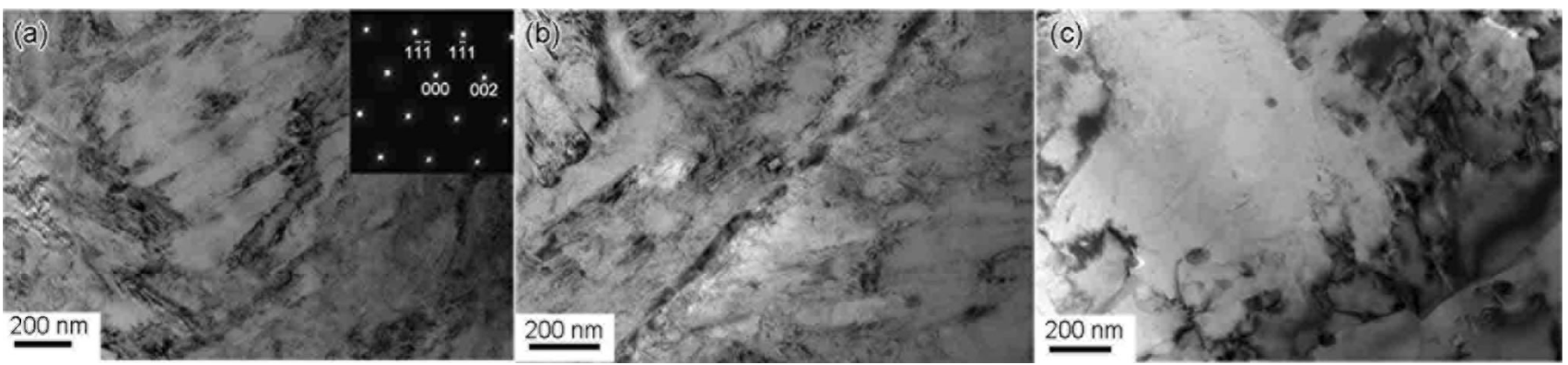

Fig. 6 TEM micrograph of thixoforging specimen a and after different heat treatments: b $200{ }^{\circ} \mathrm{C}$, c $550{ }^{\circ} \mathrm{C}$, inner area (insets show the corresponding SAED pattern)
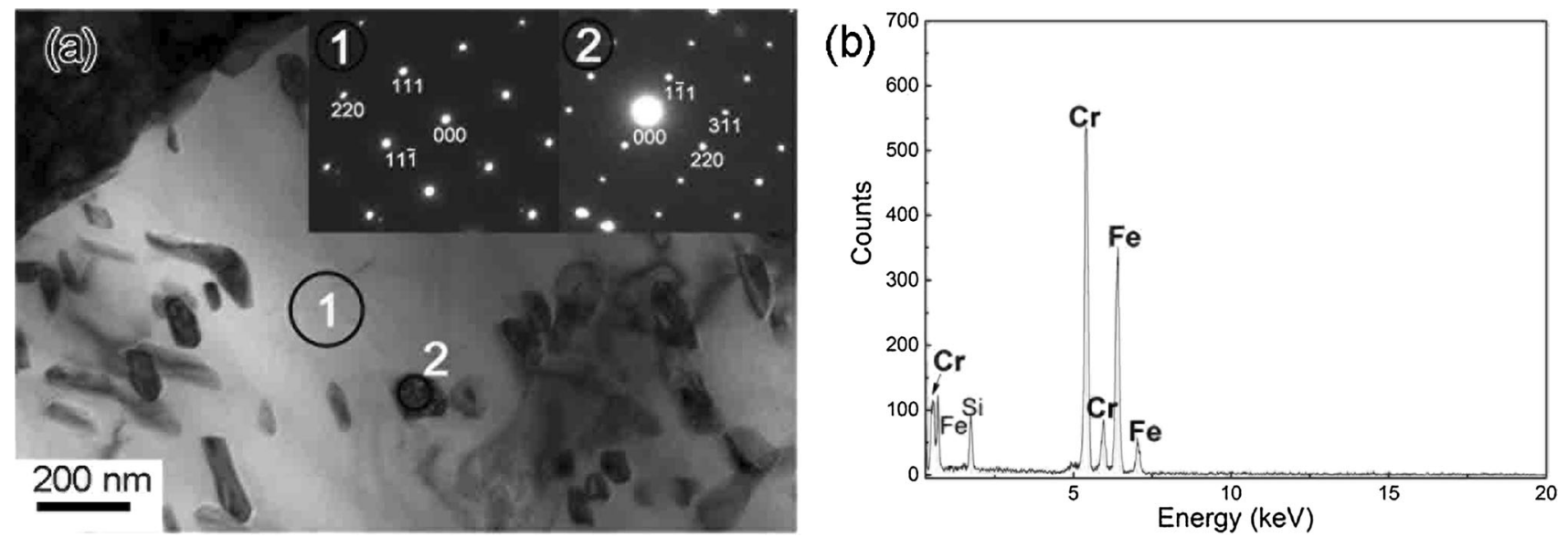

Fig. 7 a TEM micrograph of thixoforging specimen annealed at $700{ }^{\circ} \mathrm{C}$, inner area (insets show the corresponding SAED pattern); b EDS analysis of $M_{23} \mathrm{C}_{6}$

carbide by the SAED pattern. The EDS analysis of $M_{23} \mathrm{C}_{6}$ precipitate is shown in Fig. 7b. According to the SAED pattern, the inner matrix of T-700 specimen remains austenite structure, which is in accordance with the XRD result. For T-800 specimen, the chromium carbides can be seen in Fig. 8a. At the same time, martensite structure can be also confirmed besides the carbides as shown in the SAED pattern. The transformation of martensite structure leads to the increase of hardness. As shown in Fig. 8b, obvious martensite laths can be seen and it seems that most of the view field is comprised of martensite laths.
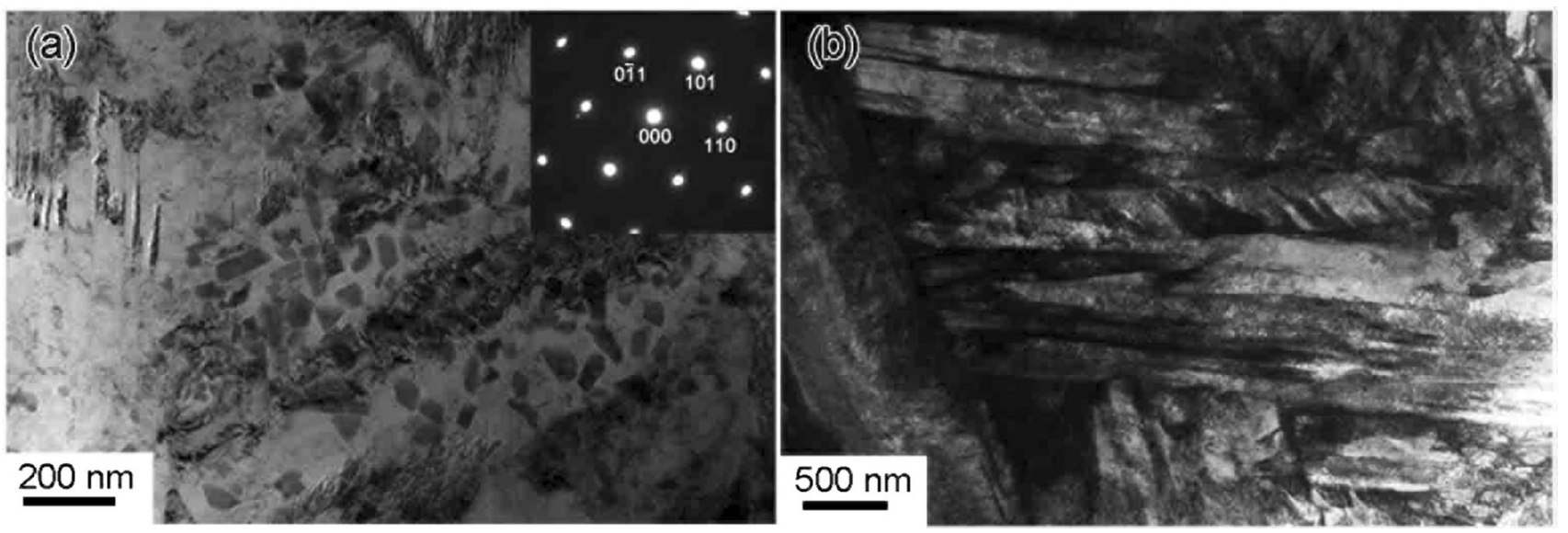

Fig. 8 TEM micrograph of thixoforging specimen annealed at $\mathbf{a} 800{ }^{\circ} \mathrm{C}, \mathbf{b} 1050{ }^{\circ} \mathrm{C}$, inner area (insets show the corresponding SAED pattern of the matrix) 
In the edge area, eutectic structure of bar-shape $M_{7} \mathrm{C}_{3}$ carbide and secondary austenite can be observed. The $M_{7} \mathrm{C}_{3}$ carbide can be confirmed by the SAED and EDS as shown in Fig. 9a, d. According to thermodynamic calculation [10], the microstructure is the result of eutectic transformation and it belongs to a kind of solidification structure. With the increase of annealing temperature, the large size of $M_{7} \mathrm{C}_{3}$ carbide begins to decompose. Thus, the size of carbide decreases. For thixoforging specimen, the width of bar-shape carbide is about $359 \mathrm{~nm}$. It reduces to $178 \mathrm{~nm}$ after annealing at $550{ }^{\circ} \mathrm{C}$. The width decreases to $56 \mathrm{~nm}$ after annealing at $800{ }^{\circ} \mathrm{C}$.

\subsection{Mechanical Properties After Different Annealing Temperatures}

The stress-strain curves in inner area after various annealing temperatures are shown in Fig. 10a. The characterization of stress-strain curves can be divided into two groups. When annealing temperature is below $550{ }^{\circ} \mathrm{C}$, a long continuous strain hardening can be seen. On the other hand, the stress-strain curves demonstrate a short strain hardening when annealing temperature is above $700{ }^{\circ} \mathrm{C}$.
Figure 10b shows the data obtained from the stress-strain curves. The yield strengths $\left(R_{\mathrm{pc} 0.2}\right)$ remain quite low for thixoforging, T-200 and T-550 specimens. But, the compression ratio $(\delta)$ and compressive strength $\left(R_{\mathrm{mc}}\right)$ increase gradually. The $\delta$ is $53.2 \%$ and the $R_{\mathrm{mc}}$ is $4680 \mathrm{MPa}$ for $\mathrm{T}-550$ specimen. Both of the values reach the highest level when annealing temperature is $550{ }^{\circ} \mathrm{C}$. When annealing temperature increases up to $700{ }^{\circ} \mathrm{C}$, the values of $\delta$ and $R_{\mathrm{mc}}$ drop sharply. The $R_{\mathrm{pc} 0.2}$ increases for T-700 specimen and the $R_{\mathrm{pc} 0.2}$ remains an increasing trend with the increase of annealing temperature. On the contrary, the $\delta$ decreases when annealing temperature is above $700{ }^{\circ} \mathrm{C}$, which shows the reduction of plasticity.

\section{Discussion}

The different morphologies of carbides in the inner and edge area are determined by the whole processing procedure. According to previous study [16], the content of chemical elements for each phase is different in semi-solid temperature range. Alloying elements are the key factor to determine microstructure evolution during cooling and
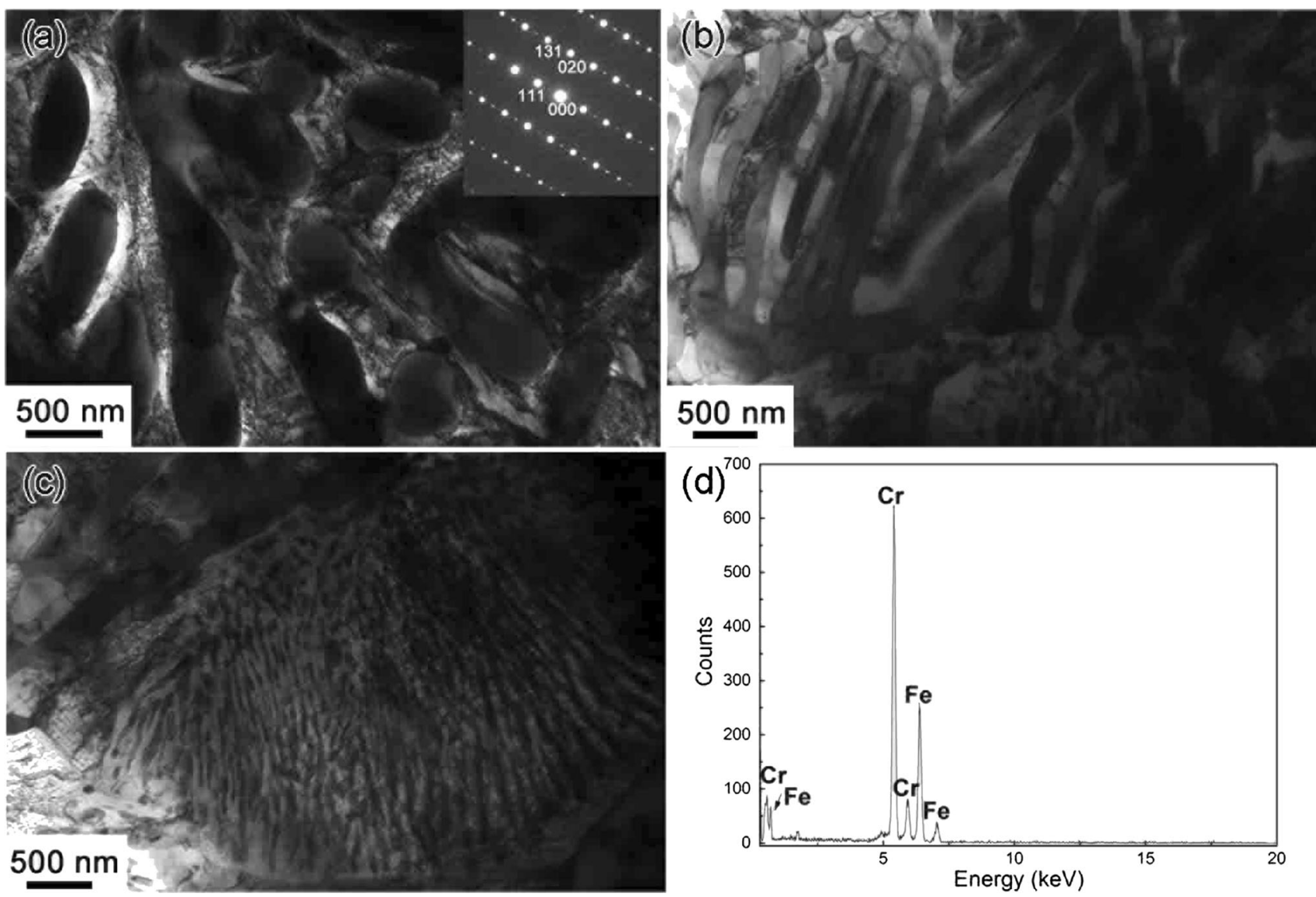

Fig. 9 TEM micrographs of thixoforging specimen a and after different heat treatments: $\mathbf{b} 550{ }^{\circ} \mathrm{C}, \mathbf{c} 800{ }^{\circ} \mathrm{C}$ in the edge area, $\mathbf{d}$ EDS analysis of $M_{7} \mathrm{C}_{3}$ (insets show the corresponding SAED pattern) 

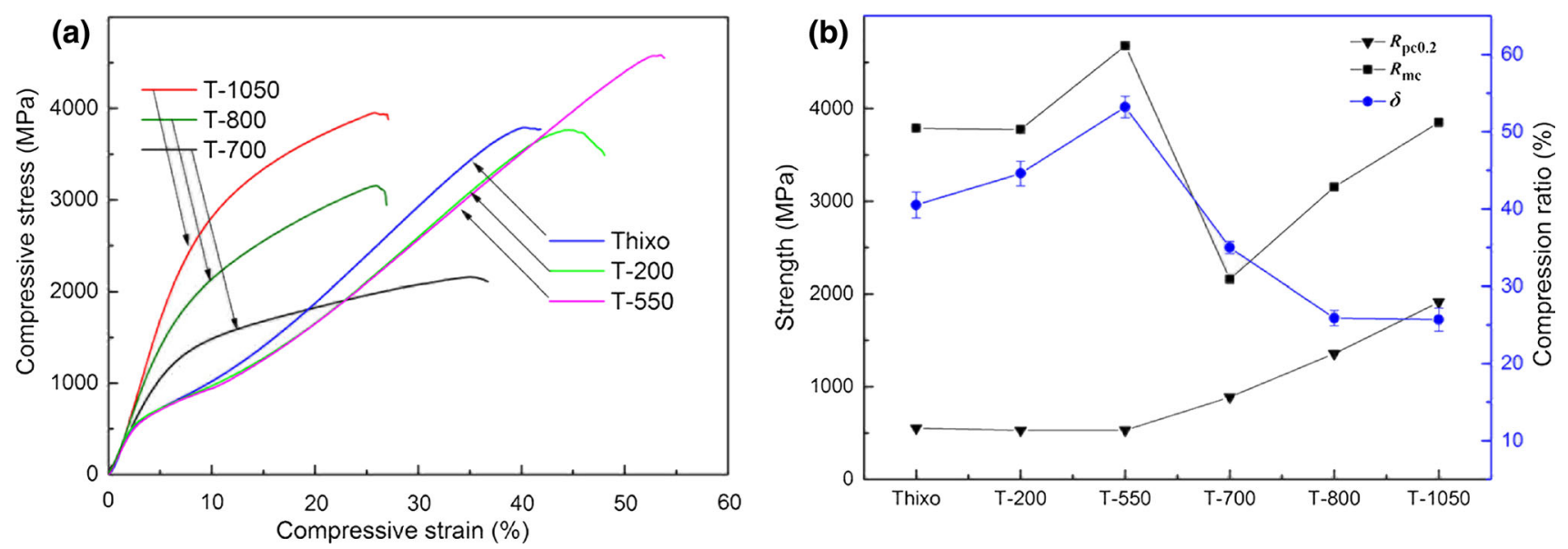

Fig. 10 a Compressive stress-strain curves of specimens after different heat treatments, $\mathbf{b}$ the analysis of mechanical values

subsequent annealing [22]. For solid phase, the high alloying elements of $\mathrm{Cr}$ and $\mathrm{C}$ stabilize the austenite after fast cooling [23]. The over-saturate austenite remains at a meta-stable state. During subsequent annealing, carbide may precipitate from austenite matrix due to the effect of thermodynamics. The behavior from inner area is similar to those of aluminum alloy: solution and aging treatment [24]. As the annealing temperature increases up to $700{ }^{\circ} \mathrm{C}$, $M_{23} \mathrm{C}_{6}$ carbide starts to precipitate. The carbide precipitation leads to the exothermic peak in DSC curve. The $M_{23} \mathrm{C}_{6}$ carbide is rich in carbon and chromium [25]. The stability of meta-austenite will decrease after carbide precipitation due to the decrease of alloying elements [26]. But, matrix austenite can be retained at this temperature. When temperature reaches $800{ }^{\circ} \mathrm{C}$, more $M_{23} \mathrm{C}_{6}$ carbides precipitate from the matrix. Meta-austenite with less alloying elements transforms into martensite due to the increase of martensite starting temperature. This phenomenon is usually called secondary hardening [27]. The endothermic peak is the result of martensite transformation. The formation of martensite structure leads to the increase of hardness as shown in Fig. 5. For liquid phase, solidification process occurs during fast cooling. As discussed above, the liquid will undergo the eutectic transformation, $\left(\mathrm{L} \rightarrow \gamma+M_{7} C_{3}\right)$. The large scale bar-shape eutectic carbide may be decomposed during annealing and the thickness of carbide decreases with the increase of annealing temperature. There are two kinds of chromium carbides: the fine precipitated $M_{23} \mathrm{C}_{6}$ carbide in the inner area and the coarse eutectic bar-shape $M_{7} \mathrm{C}_{3}$ carbide in the edge area. The carbide evolution behavior is different in the two areas. Therefore, the thixoforging specimen can be designed to be a functional gradient material with a tough center and hard surface. Carbide evolution will directly influence the microstructure characterization.
The mechanical properties are linked with the phase transformation [28] and carbide precipitation [29]. For the functional gradient component, the inner area will bear the strength and toughness. The solid particles are almost connected without liquid film, which will help to improve the mechanical properties [30]. For thixoforging, T-200 and T-550 specimens, no obvious phase transformation or carbide precipitation can be observed. The soft austenite structure explains the low yield strength. The low temperature annealing process helps to release the internal residual stress caused by semi-solid fast cooling. Thus, the $\delta$ and $R_{\mathrm{mc}}$ are improved and reach the highest level when annealing temperature is $550{ }^{\circ} \mathrm{C}$. The pure FCC austenite matrix explains the long continuous strain hardening. When annealing temperature increases up to $700{ }^{\circ} \mathrm{C}$, the occurrence of $M_{23} \mathrm{C}_{6}$ carbide will be harmful to the continuous strain hardening. Thus, the $\delta$ decreases. The $M_{23} \mathrm{C}_{6}$ carbide can play a role in precipitation strengthening at the same time. Therefore, the $R_{\mathrm{pc} 0.2}$ increases a bit as compared with pure austenite matrix specimens. Since the matrix is still austenite structure for T-700 specimen, the final $R_{\mathrm{mc}}$ is lower than the martensite-based T-800 and $\mathrm{T}-1050$ specimens. When the matrix transforms into martensite for $\mathrm{T}-800$ and $\mathrm{T}-1050$ specimens, the yield strength is improved, while the plasticity decreases due to the brittle martensite and carbide precipitation. By controlling the carbide evolution, we can tailor the functional gradient material with required property.

\section{Conclusions}

A functional gradient material is fabricated by thixoforging. The inner and edge areas of thixoforging specimen demonstrate different microstructure evolution behaviors. 
1. In the inner area, solid particles are retained as metaaustenite after fast cooling. Austenite structure is stable after low temperature annealing. The granular $M_{23} \mathrm{C}_{6}$ carbide begins to precipitate when annealing temperature reaches $700{ }^{\circ} \mathrm{C}$. Martensite transformation occurs when annealing temperature reaches $800{ }^{\circ} \mathrm{C}$. The formation of martensite structure leads to the increase of hardness.

2. In the edge area, liquid undergoes eutectic transformation to form bar-shape $M_{7} \mathrm{C}_{3}$ carbide and secondary austenite. The width of bar-shape carbide would decrease during annealing.

3. Low temperature annealing process helps to release the internal residual stress. Compression ratio and compressive strength stress reach highest level when annealing temperature is $550{ }^{\circ} \mathrm{C}$. The occurrences of $M_{23} \mathrm{C}_{6}$ carbide and martensite transformation would be harmful to the mechanical properties in inner area.

Acknowledgements The research was supported by the National Natural Science Foundation of China (No. 51175036) and the authors are also grateful to the support from the China Scholarship Council (CSC) (Grant No. 201606460014).

\section{References}

[1] T. Balan, E. Becker, L. Langlois, R. Bigot, CIRP Ann. Manuf. Technol. 66, 297 (2017)

[2] M. Rosso, I. Peter, Int. J. Micro. Mater. Prop. 8, 113 (2013)

[3] A. Neag, V. Favier, R. Bigot, M. Pop, J. Mater. Proc. Technol. 212, $1472(2012)$

[4] R.G. Guan, Z.Y. Zhao, X. Wang, C.G. Dai, C.M. Liu, Acta Metall. Sin. (Engl. Lett.) 26, 293 (2013)

[5] R.G. Guan, Y.F. Shen, Z.Y. Zhao, R.D.K. Misra, Sci. Rep. 6, 23154 (2016)

[6] S.P. Midson, Solid State Phenom. 217-218, 487 (2014)
[7] K.M. Kareh, C.O. Sullivan, T. Nagira, H. Yasuda, C.M. Gourlay, Acta Mater. 125, 187 (2017)

[8] L. Rogal, J. Dutkiewicz, Metall. Trans. A 43, 5009 (2012)

[9] G.C. Gu, R. Pesci, L. Langlois, E. Becker, R. Bigot, J. Mater. Proc. Technol. 216, 178 (2015)

[10] D. Uhlenhaut, J. Kradolfer, W. Puttgen, J. Loffler, P. Uggowitzer, Acta Mater. 54, 2727 (2006)

[11] L. Rogal, G. Korpala, J. Dutkiewicz, Mater. Sci. Eng., A 624, 291 (2015)

[12] C. Solenthaler, M. Ramesh, P.J. Uggowitzer, R. Spolenak, Mater. Sci. Eng., A 647, 294 (2015)

[13] J. Dong, X. Zhou, Y. Liu, C. Li, Mater. Sci. Eng., A 683, 215 (2017)

[14] Y. Li, Y. Gao, B. Xiao, B. Xiao, T. Min, Y. Yang, S. Ma, D. Yi, J. Alloy. Compd. 509, 5242 (2011)

[15] C.Q. Zhao, R.B. Song, Mater. Des. 59, 502 (2014)

[16] Y.J. Wang, R.B. Song, Y.P. Li, Mater. Charact. 127, 64 (2017)

[17] Y.J. Wang, R.B. Song, Y.P. Li, Mater. Des. 86, 41 (2015)

[18] A. Rassili, Solid State Phenom. 256, 228 (2016)

[19] Y. Meng, J.S. Zhang, Y.S. Yi, J. Zhou, S. Sugiyama, J. Yanagimoto, J. Mater. Proc. Technol. 248, 275 (2017)

[20] C.Y. Xiong, P.F. Xue, F. Zhang, Y. Li, Mater. Charact. 133, 156 (2017)

[21] Y.H. Zhou, Y.C. Liu, X.S. Zhou, C.X. Liu, J.X. Yu, Y. Huang, H.J. Li, W.Y. Li, J. Mater. Sci. Technol. 33, 1448 (2017)

[22] D. Aisman, H. Jirkova, L. Kucerova, B. Masek, J. Alloy. Compd. 509, S312 (2011)

[23] W. Puttgen, B. Hallstedt, W. Bleck, P.J. Uggowitzer, Acta Mater. 55, 1033 (2007)

[24] X. Luo, Y.Z. Liu, B. Wang, Acta Metall. Sin. (Engl. Lett.) 28, $1305(2015)$

[25] X.S. Zhou, Y.C. Liu, C.X. Liu, L.M. Yu, H.J. Li, Mater. Res. Innov. 19, S193 (2015)

[26] B.Q. Ning, X.S. Zhou, Q.Z. Shi, Y.C. Liu, J. Zhao, Z.P. Zhang, Int. J. Mater. Res. 105, 232 (2014)

[27] E. Smith, Acta Metal. 14, 583 (1966)

[28] S. Hong, Y.P. Wu, G.Y. Li, W.W. Gao, G.B. Ying, J. Alloy. Compd. 581, 398 (2013)

[29] J. Liu, W.P. Chen, Z.F. Jiang, L.S. Liu, Z.Q. Fu, Vacuum 137, 183 (2017)

[30] L. Rogal, J. Dutkiewicz, Mater. Charact. 68, 123 (2012) 